\title{
Economic and Welfare Effects of the Abolition of Health User Fees: Evidence from Uganda
}

\author{
Klaus Deininger* \\ Paul Mpuga*"
}

\author{
${ }^{*}$ The World Bank, Washington D.C. \\ *** Johannes Kepler University, Linz-Austria \& \\ Makerere University, Kampala-Uganda
}

\section{World Bank Policy Research Working Paper 3276, April 2004}

The Policy Research Working Paper Series disseminates the findings of work in progress to encourage the exchange of ideas about development issues. An objective of the series is to get the findings out quickly, even if the presentations are less than fully polished. The papers carry the names of the authors and should be cited accordingly. The findings, interpretations, and conclusions expressed in this paper are entirely those of the authors. They do not necessarily represent the view of the World Bank, its Executive Directors, or the countries they represent. Policy Research Working Papers are available online at http:/lecon.worldbank.org.

We thank the Uganda Bureau of Statistics, especially James Muwonge and Tom Emwanu, for making the data available. Support from the African Statistical Capacity Building Initiative and the Norwegian ESSD Trust Fund is gratefully acknowledged. 


\title{
Economic and Welfare Effects of the Abolition of Health User Fees: Evidence from Uganda
}

\begin{abstract}
Household level data for Uganda for 1999/2000 and 2002/03, before and after the abolition of user fees for public health services, are used to explore the impact of this policy on different groups' ability to access health services and morbidity outcomes. We find that the policy change improved access and reduced the probability of sickness in a way that was particularly beneficial to the poor. Although the challenge of maintaining service quality remains, aggregate benefits are estimated to be significantly larger than the estimated shortfalls from the abolition of user fees.
\end{abstract}

Keywords: User fees, health outcomes, health care services, public and private health care centres

\section{Introduction}

Few interventions in the area of public service provision have been as controversial and subject to as fierce a debate as the imposition of user fees for health services. Some think that at least a moderate level of cost recovery is justifiable to put social services on a more sound footing and that potential negative side effects from a modest user fee for health treatment are a small price to pay for the increased accountability and improvement in service quality that can be achieved through such a measure. Others hold equally firm views to the opposite, thinking that charging for treatment will strongly discriminate against the poor who, especially in an economy that is still largely based on subsistence, will be hard pressed to come up with the cash required to make such payments. Even though, on theoretical grounds, both outcomes are possible, what happens in practice will have far-reaching implications for the ability of the poor to access health care and thus to realize their full economic potential. To make informed policy decisions, empirical evidence to identify, in any given setting, the relevant factor, will therefore be critical.

Indeed, a large number of studies from developing countries have aimed to provide empirical evidence to support claims regarding user fees for health services. However, in many cases the analysis is based on the level of access to public health services rather than on changes that have been associated with a specific reform that aimed to change such access, thereby making it more difficult to distinguish between pre-existing structural characteristics of the system and a certain policy (Gwatkin, 2000). Furthermore, the scarcity of good and comprehensive socio-economic data on health access has forced analysts in many instances to rely on administrative data sources that tend to be insufficient to make behavioral inferences or to allow in-depth assessment of the incidence of access to health services that are critical in order to judge the impact of a specific policy on equity. Finally, analyses that focus only on those who actually 
make use of health services will suffer from censoring and lack the representativeness required to allow extrapolation for a larger population. Taken together, these factors imply that strong conclusions on specific policies are in some cases arrived at based on inadequate empirical foundations or do not allow inferences on the broader economic and social costs and benefits of an intervention.

In this paper we aim to contribute to the emerging literature on this topic by exploring the impact of the abolition of health user fees in Uganda. In doing so we expand on the available literature, which consists mainly of case studies with a limited outreach, in a number of respects. First, while most empirical studies have explored the impact of imposing health user fees, we focus on the abolition of such fees, assessing in particular whether doing so has helped the poor gain greater access to curative services and to reduce overall morbidity in the population. Second, in addition to administrative data, we draw on data from two large-scale nationally representative household surveys, before and after this intervention, to assess the impact of this measure on the change in individuals' probability of accessing health services and the associated health outcomes. Finally, we exploit regression results to compute the change in households' expected level of sickness, which, valued at the prevailing wage rate for unskilled labor, provides a lower bound for the economic benefits associated with the abolition of user fees. This allows us to draw inferences on the incidence of benefits from this policy in terms of time that is spent working rather than tending sicknesses. More interestingly, we can, by comparing the overall economic benefits to the costs in terms of foregone revenue from user fees, arrive at a measure of social costs and benefits of the policy change that are nationally representative and that may be of interest for the debate beyond Uganda.

We find that the abolition of user fees significantly improved access to health services especially by the poor, whose spending on health (at the household level) is significantly reduced after the policy change. The fact that there is little change in aggregate spending on health suggests that at least to some degree those who are better off may have opted out of the public system in favor of private providers. There is also evidence of a clear reduction in the incidence of morbidity and the elimination of asset bias in access to treatment that had characterized the system before the abolition of user charges. Comparing the revenues that health establishments have had to forgo as a result of the elimination of user charges to the value of the time that was, after the reform, spent working rather than treating sicknesses suggests that the benefits from the policy change exceed the costs and allows us to draw implications in a number of dimensions.

The paper is structured as follows. Section 2 reviews the literature and describes the situation of public health services in Uganda and the data used. In addition to providing a number of descriptive statistics, the section examines to what extent there is a link between increased cost recovery and improved quality of service delivery in a number of dimensions. Section 3 explores determinants of health service 
utilization, including user fees and health outcomes. Section 4 presents empirical results on incidence of sickness and health outcomes before and after abolition of use fees, and Section 5 concludes.

\section{Background, literature and data sources}

To set the scene, this section reviews the discussion in the literature on the pros and cons of user fees for health care as well as the evidence on the impact of this measure. We then describe the evolution of Uganda's health system over time, in particular the imposition and subsequent elimination of user charges for health services, and use DHS data on health outcomes to place the quality of Uganda's health services in a comparative international perspective.

\subsection{User fees for health services: Conceptual foundations and empirical evidence}

While equity concerns have originally motivated many developing country governments to provide health services for free, such services were often not well targeted, implying that increasingly large amounts of resources had to be expended to provide them. With the imperative to balance budgets, such services often were no longer affordable. To prevent fiscal constraints from undermining the quality of the health system, policy makers have increasingly emphasized the need to focus public support on provision of a basic package of primary health care and to impose some cost recovery in the form of user fees wherever possible (Gwatkin, 2000). A justification for such policies was provided by studies that showed demand for health care to be relatively inelastic with respect to price (McPake, 1993; Akin et al. 1985; Heller, 1982; Birdsall and Orivel, 1983; Jimenez, 1985), implying that potential users would be willing to pay for services that were of a sufficiently high quality. This general policy direction has been expressed in the Bamako Initiative, which was supported by a large number of governments (Gilson et al., 2000; McPake et al., 1993).

The shift toward greater cost recovery prompted a rapid growth in empirical studies aiming to determine whether cost recovery promotes or prevents access to health care by the poor (see Shaw and Ainsworth, 1995; Reddy and Vandermoortele, 1993; Gilson et al., 2000; Akin et al., 1989 for summaries). Proponents of user fees argued that at least part of the benefits from better health are private goods and that even charges that fall far short of full cost recovery can prevent those seeking health care from overusing the system while, especially if appropriately channeled, providing incentives for better performance of medical staff (Audibert and Mathonnat, 2000; Killingsworth et al., 1999; de Ferranti, 1985). The general consensus, as supported by recent empirical evidence, seems to be that in a number of cases the poor are willing to pay for high quality of health services, such that user fees may not hamper their access to health care. For example, evidence from Bangladesh points to instances where the poor 
bypassed free or cheap government institutions and traveled further to more expensive establishments that offered acceptable quality (Akin and Hutchinson, 1999). Introduction of user fees in Mauritania in 1992 is reported to have not only helped to improve the quality of health care but also improved facilities and the ability to invest in upgrading and training (Audibert and Mathonnat, 2000). Similarly in Niger, no evidence of serious reductions in access or increases in cost could be found when investigating the impact of implementing direct user charges that were combined with insurance payments and improved service quality. In fact, higher utilization of formal health care, which is surmised to be due to improvements in quality, is reported to have outweighed any possible decrease in utilization due to increased costs (Chawla and Ellis, 2000). Higher quality of services that followed health care fees in Cameroon implied that the fees constituted a reduction in the effective price of health services and led to increased utilization of the services, with no visible negative impact on the poor (Litvack and Bodart, 1993). Introduction of user fees is found to receive broad support if such fees eliminate the often significant charges and bribery that are often levied unofficially, in which case the negative impact on equity is likely to be limited (Killingsworth et al., 1999). Evidence that the poor bypass cheap public health centers in preference for private ones has been interpreted to imply that charging of user fees, if accompanied by improvements in quality, can be justified and would not have a negative impact on equity, suggesting that governments should therefore focus on financing rather than direct provision of health services.

On the other hand, the policy has since not received universal acceptance and has been questioned due to its potentially negative impacts on equity (McPake, 1993; Creese, 1991; Gertler and van der Gaag, 1990), and the fact that the potential for revenue generation seems to have been exaggerated (McPake, 1993; Creese, 1991; Gilson et al., 2000). It has also been pointed out that credit constraints may limit the ability to access fee-based services even when there is a clear willingness to pay (Hausman-Muela et al., 2000). This has been used to argue that the largely symbolic nature of such contributions makes them inappropriate as a mechanism to generate revenues (and in some cases the revenues generated are less than the cost of collection) and that the only effect of user fees is to exclude the poor who, from a social point of view, should be most entitled to health services (Nyonator and Kutzin, 1999).

Some contributions to the literature have shown user fees to be associated with reduced access to health care, particularly by the poor. In Ghana, for example, although increased cost recovery was perceived to be associated with increased quality of service delivery and drug supplies, it led to higher levels of selfmedication and other types of behavior aimed at cost saving by the poor (Asenso-Okyere et al., 1998). While this can in principle be overcome by well-designed fees and exemptions for the poor, applying and enforcing such targeting has been shown to be difficult in practice (Nyonator and Kutzin, 1999; Kapiriri 
et al. 2003). As a consequence, imposition of user charges may possibly result in significant negative externalities that could outweigh any fiscal savings (McPake, 1993; Creese, 1991; Gilson et al., 2000).

While the design of user fees for health is a highly relevant policy question with significant and farreaching implications for the poor, the ability to respond to and assess the impact of such policies is often constrained by data availability. Lack of data on service provision at the facility level makes it difficult to ascertain the extent to which the expected improvement in service quality has indeed materialized. Administrative data that lack information on users' socio-economic characteristics make it difficult to identify the poor and thus assess how they are affected by reforms of health financing. Inability to control for other factors, such as the provision of infrastructure complementary to health services, makes it difficult to assess the trade-offs involved and to decide whether government should invest in health related services rather than, say, improving water supply. This paper explores the issue at hand with respect to the supply of health services, households' demand for such services, and actual outcomes before and after the abolition of cost sharing in Uganda.

\subsection{The public health system in Uganda}

Public or government hospitals in Uganda are graded in three categories; national referral, regional referral and district/rural hospitals. ${ }^{1}$ At the time of independence in 1962, Uganda had one of the best public health care systems in Africa. The country was characterized not only by the largest and best equipped referral hospital in the region, but also had a well-functioning hospital in virtually every district, in addition to well-equipped dispensaries at the county and sub-county levels. Health care services were provided free of charge, and access to care was good. Following neglect and mismanagement in the 1970s and early 1980s, massive deterioration ensued. Today, the quality of many public health facilities is poor; they are characterized by underpaid and demoralized staff, together with shortages of trained personnel and medical equipment. A 1996 survey indicates that only between one-quarter and one-third of those requiring health care used government health facilities because of frequent lack of drugs, poor facilities, absence of qualified health workers, and long waiting times (Ablo and Reinikka, 1998). Private sector

\footnotetext{
${ }^{1}$ Facilities are further graded as Health Centre (HC) II, III, and IV, depending on the administrative zone served by the facility; parish, subcounty and health sub-district. At the parish level, the HC II provides outpatient and ante-natal care, immunisation and outreach. It is normally managed by an enrolled nurse assisted by an enrolled midwife and two nursing assistants. At the sub-county level, the HC III, with one clinical officer, one enrolled nurse, two enrolled midwives and one nursing assistant, one health assistant, one laboratory assistant and a records officer, is expected to provide all the services mentioned earlier plus inpatient care and environmental health. At the health sub-district level, a HC IV has at least one medical officer, two clinical officers, one registered midwife, one enrolled nurse, one enrolled midwife, one comprehensive nurse, two nursing assistants, one laboratory technician, laboratory assistant, health inspector, dispenser, public health dental assistant, anaesthetic officer, assistant health educator, record's assistant, accounts assistant and two support staff. It is expected to provide the services mentioned earlier plus surgery. In addition, it supervises lower level units, collects and analyses data on health, and elaborates plans for the health subdistrict. Given limited government funding, many of these units suffer from inadequate staffing and have difficulty in complying with these goals.
} 
providers, including clinics, health centres and hospitals that are mostly operated on a cost-recovery basis, have sprung up to partly make up for the shortfall. ${ }^{2}$

To improve performance of the public health system, a number of reforms, including decentralization, imposition of user charges, and finally abolition of such charges, have been undertaken, starting in 1989. Decentralization was expected to bring bout administrative and structural changes in the health delivery system with the goal of improving coverage and equity as well as technical and allocative efficiency. ${ }^{3}$ To this end, efforts were initiated to restore the functional capacity of the health sector, reactivate disease control programs, and re-orient services to preventive and primary care rather than curative interventions.

First attempts to introduce user charges in 1990 met with opposition motivated by fears that such fees would preclude access to health services by the poor. However, given the limitations on public funds, the central government in 1993 actively promoted introduction of user fees by the already decentralized districts to improve delivery of health services. The level of fees was set at UShs500 for adults and UShs300 for children in rural areas and up to Ushs 1,000 and Ushs500 for adults and children, respectively, in urban areas. ${ }^{4}$ A recent comprehensive study of actual user fees shows that, as districts had considerable autonomy in setting fee levels, actual charges varied considerably, although they were consistently below comparable fees charged by private establishments (Lindelow et al., 2003). Case study evidence suggests that most of the fees were used to supplement staff salaries (Mwesigye 2002), implying a rather limited impact on revenue generation by health establishments.

Even though the law contained provisions to exempt the poor from payment of user fees, case study evidence shows that the inability of districts to compensate for such shortfalls from other sources made them very reluctant to implement such exemptions, implying that fees were assessed in a fairly uniform manner (Kapiriri et al. 2003). This led to repeated complaints that the fees excluded the poor who, for various reasons, did not have the cash to pay them (Kivumbi and Kintu, 2002). These complaints provided the basis for abolition of all user charges in the health sector, effective from March 2001, coinciding with the Presidential elections. To this date, it is not clear what the impact of this policy change has been, in terms of access to health services by the poor. Providing evidence that would allow such an assessment is one of the goals of this paper.

\footnotetext{
${ }^{2}$ Currently, the Ministry of Health (MOH) estimates the total number of health service outlets in the country to be 1,738 facilities, of which 1,226 are government-owned/managed, 465 belong to NGOs and 47 belong to the private sector. The facilities include 104 hospitals (57 government, 44 NGO and 3 Private), 250 health centres (179 government, 68 NGO and 3 private), palliative care 2 (1 government, 1 NGO) and others (989 government, 352 NGO and 41 private), (Reinikka and Svensson, 2003; Republic of Uganda, 2001 and 1997).

${ }^{3}$ Under the new arrangements, the district health system is used to deliver a package of health services to the population, while the MOH is responsible for policy formulation, standards and guidelines, overall supervision and monitoring (Republic of Uganda, 2000a and 2000b).

${ }^{4}$ At the time when the changes were introduced, this was equivalent to about US $\$ 0.45$ (the exchange rate fluctuating around USh1,000 to US $\$ 1)$. The revenue to be generated from such user fees was to be used to top-up staff salaries (50\%), purchase drugs and supplies (30\%), maintenance and repairs of facilities (10\%), supervision, transport and outreach $(10 \%),(\mathrm{MOH}, 1997)$.
} 
Before doing so, we use data from the Demographic and Health Survey (DHS) to describe the health characteristics and to gain an appreciation of the quality of health services in Uganda over time and in international comparison. ${ }^{5}$ The upper panel of table 1 uses DHS data, all of which were collected before the abolition of user fees, to highlight that, even though Uganda's health system had improved considerably before 1995, the rate of improvement had slowed considerably, and was in some cases even reversed, thereafter. For example, one notes that infant mortality for children under the age of one (in deaths per 1,000 live births) declined from 98 in 1988 to 81 in 1995 but then increased to 88 in 2001. Coverage of 1-2 year old children with BCG vaccinations improved from about 41\% and those for DPT3, polio and measles improved from slightly above $20 \%$ in 1988 to $79 \%, 55 \%, 53 \%$ and $45 \%$ in 1995 , just to drop to $75 \%, 42 \%, 50 \%$ and $42 \%$ for BCG, DPT3, polio, and measles, respectively, in 2000. Progress in reducing the prevalence of diarrhea, stunting, and antenatal care slowed down or stalled in 1995-2001 as compared to 1988-95. This drop in health indicators is even more puzzling as it occurred in a period that, according to available macro statistics and household surveys, was characterized by high levels of economic growth and significant reduction in poverty (UBOS, 2001; Appleton, 2001). As the survey dates do not coincide with the periods before and after the imposition of user fees, it is impossible to establish a clear relationship. The marked slowdown of service quality is often interpreted in the sense that, rather than improving quality and access, imposition of user fees may indeed have either decreased the outreach of the health system or at least slowed down progress (Mwesigye, 2002).

Comparing Uganda with other African countries, as in the lower panel of table 1, adds to the questions by illustrating that, even for Africa, the country ranks close to the bottom for many of the indicators conventionally used to compare quality of health delivery systems. Rates of infant mortality in Ghana, Kenya, Nigeria and Zimbabwe were significantly lower than those of Uganda for most of the periods under concern, notwithstanding the fact that some of these countries also failed to make consistent progress in reducing infant mortality. With the exception of Nigeria (and Burkina Faso in the case of stunting), Uganda has the lowest vaccinations coverage, and the highest incidence of stunting and prevalence of diarrhea, compared with the other countries in the sample. The fact that in Uganda, coverage with antenatal care was among the highest for all of Africa suggests that there were differences across types of health services but at the same time raises the possibility that the problem may have been related to access. Below we explore to what extent the abolition of user charges may have helped to improve this without affecting the quality of service provision.

\footnotetext{
${ }^{5}$ Demographic and health surveys, which have been conducted in a large number of developing countries, with significant support from USAID, provide information on family planning, maternal and child health, child survival, HIV/AIDS/sexually transmitted infections (STIs), and reproductive health to monitor and evaluate population, health, and nutrition programs. For more information see http://www.measuredhs.com/.
} 


\section{Conceptual framework, methodology and estimation strategy}

This section discusses the conceptual framework and estimation strategy as well as the data to be used. We expect that the decrease in the price of health services through elimination of user fees would imply a reduction in the extent to which individual users are rationed out of the use of such services. While the impact on the balance between private and public is less easy to predict as it depends in part on unobservable quality characteristics, less rationing should be associated with a reduction in morbidity, at least to the extent that quality can be maintained. Descriptive statistics from the two household surveys are used to provide some evidence on this and suggest that there was at least some change that would be worth exploring in more detail econometrically.

\subsection{Conceptual model and hypotheses}

Assume that individuals maximize a well-behaved utility function $U(c)$ over consumption subject to a budget constraint $Y(\boldsymbol{p}, \boldsymbol{I}, \boldsymbol{H})$ where $\boldsymbol{p}$ is a vector of prices and $\boldsymbol{I}$ and $\boldsymbol{H}$ are vectors of individual and household characteristics, respectively and where $\boldsymbol{I}$ includes an indicator, S, of whether or not the person is sick. Let $p_{P}$ and $q_{P}$ represent the price and quality of health services in the public sector and $p_{V}$ and $q_{V}$ price and quality in the private sector. Then the demand for health services of a sick person (i.e. $\mathrm{S}=1$ ) can be written as $D\left(p_{P}, q_{P} p_{V}, q_{V} ; H\right)$. We assume that the demand function follows standard assumptions, i.e. $\frac{\partial D}{\partial p_{P}}<0$ and $\frac{\partial D}{\partial q_{P}}>0$.

Abolition of user fees in the public sector is equivalent to a decrease in prices for these services from $p_{P}^{0}$ to $p_{P}^{l}$ with $p_{P}^{0}>p_{P}^{l}{ }^{6}{ }^{6}$ Under the above assumptions on the demand function, and without changes in the quality of health services, such a policy change will lead to an increase in demand, i.e. some households who previously did not use public health facilities due to price reasons may now do so. This leads us to expect that (i) the abolition of user fees led to an increase in demand for curative services by those who were sick; (ii) this increase originated in households who were unable to access curative health services for cost reasons under the regime of user fees and should therefore be of particular benefit to the poor.

As is variously implied in the literature, loss of the ability to collect user fees by the respective institutions may, however, have a negative impact on the quality of service provision. To see this, assume that $q_{P}$, the quality of service provision in the public sector, is a function of the sum of user fees obtained, i.e. $q_{P}=$ $M\left(\Sigma p_{P}\right)$. With $M^{\prime}() \geq$.0 , it is clear that $q_{P}^{l} \leq q_{P}^{0}$, i.e. the reform may have led to a decrease in quality. Data on actual use of health facilities are not the most appropriate to show this as it may take time for such a change to materialize and for (poor) users who were attracted by freely available health facilities to modify their behavior. Low quality in service provision will, however, have an immediate impact on 
morbidity, implying that it will be important to complement the evidence on use of facilities with data on actual incidence of sickness in the population to obtain a comprehensive assessment of the impact of the policy change.

Thus, while the use of health services conditional on an individual being sick is a good measure of how access to public services has improved, it fails to measure the impact of such reforms, which is the variable of ultimate interest for policy makers. Focusing attention on the latter is important and may yield different results to the extent that the policy change is likely to have affected not only demand for curative care, but also for preventive measures. More importantly, unobserved changes in the quality of service provision will have a more immediate impact on observed health outcomes than on households' demand for such services. For these reasons, exploring the impact of the policy measure on morbidity, as measured by the probability of households falling sick or the number of days they lost due to sickness, will be necessary.

\subsection{Estimation strategy}

Facility level data: Before testing the hypotheses at the household level in more detail, we use evidence from a time series of administrative data for different types of treatment (indexed by $k$ ) to asses the impact of the policy change on changes in supply of services to the public. In the simplest form, the impact of the policy change on the amount of treatments dispensed can be obtained by a simple regression such as

$$
V_{k l t}=\alpha_{1 k} T+\alpha_{2 k} \boldsymbol{R} T+\alpha_{3 k} \boldsymbol{C}+\mu_{i}
$$

where $V_{k l t}$ denotes the logarithm of the number of services $V$ of type $k$ provided in health unit $l$ during period $t, T$ is a time dummy that equals 1 if the observation comes from after the abolition of user fees and 0 otherwise, $\boldsymbol{R}$ is a vector of regional dummies and $\boldsymbol{C}$ is a vector of controls as explained below. The underlying principle is that the coefficient $\alpha_{1 k}$-or different elements of the coefficient vector $\alpha_{2 k^{-}}$ correspond to the mean percentage increase in service delivery after abolition of user fees and after controlling for other factors. ${ }^{7}$ The latter include the fact that data are not available at the facility but at the district level and that there are gaps in the level of reporting by different facilities. We therefore report in table 5 the coefficients $\alpha_{1 k}$ or the four coefficients $\alpha_{2 k}$ for different types of services $(k)$ together with their level of significance and the number of observations used in each of the regressions.

While equation (1) will provide a first indication of the impact of the policy reform on delivery and supply of health services, it is associated with a number of shortcomings, in particular (i) it will be impossible to distinguish supply and demand; (ii) we do not know anything about the extent to which

\footnotetext{
${ }^{6}$ To keep matters simple, we assume that the price charged by private providers does not change as a result of the policy reform, an assumption that is justified if private providers do not act strategically but rather aim to cover their operating costs.
} 
higher levels of service delivery translate into reduced morbidity or other outcome variables of interest; (iii) as the data is at the facility level, it is impossible to adjust for household characteristics (e.g. wealth) that might have a significant impact; and (iv) clinics may have an incentive to mis-report, change standards over time, or otherwise behave strategically if they presume that, their access to central funds will depend on such behavior. The only way to remedy these shortcomings is to have individual data on use of health services from before and after the policy change. Below we explain how these are utilized to test the three hypotheses identified earlier.

Rationing: One clear implication from the conceptual model is that abolition of user fees is likely to have reduced the share of those who, although in need of curative treatment, were unable to access such services because of cost reasons. To test this, we define as rationed all of those who fell sick but did not use health services because the cost of doing so was too high or the facility was too far (but not because the sickness was mild) and then use a standard probit model to identify factors that had a significant impact on such rationing. In particular, we are interested whether the policy change, as approximated by a time dummy, affected the probability of being rationed. Formally, we estimate an equation of the form

$$
N_{i t}=\alpha_{0}+\alpha_{1} \boldsymbol{X}_{i t}+\alpha_{2} \boldsymbol{H}_{i t}+\alpha_{3} T+\alpha_{4} \boldsymbol{H}_{i t} T+\alpha_{5} \boldsymbol{X}_{i t} T+\mu_{i t}
$$

where $N_{i t}$ is dummy indicator for rationing of a sick individual, $\boldsymbol{X}_{i t}$ and $\boldsymbol{H}_{i t}$ are vectors of individual and household characteristics that are thought to influence the extent of rationing, and $T$ is a time dummy that equals 1 if the observation is from 2002/3, i.e. after the abolition of user fees, and 0 otherwise. The vector $\boldsymbol{X}_{i t}$ includes age, sex, and education whereas $\boldsymbol{H}_{i t}$ includes the value of household assets, dwelling characteristics such as roofing material and presence of a toilet facility, distance to the hospital, and regional dummies. Furthermore, to assess the extent to which the impact of the policy change differed with socio-economic characteristics, we interact a subset of the household and individual characteristics in $\boldsymbol{X}_{i t}$ and $\boldsymbol{H}_{i t}$ with the time dummy.

In line with the conceptual model, we expect $\alpha_{3}$, the marginal increase in the probability of rationing due to the policy change, to be negative and significant. While signs for age and sex are ambiguous a priori, we expect the coefficients on wealth and "better" dwelling and sanitary conditions to be negative and distance to the next health facility to be positive. The prediction of the policy change being favourable to the poor would translate into the absolute value of the sum of the elements of $\alpha_{2}$ and that $\alpha_{5}$ that correspond to assets and their interaction with the time dummy being smaller than the absolute value of $\alpha_{2}$. In fact, the elimination of any wealth bias in access to health services translates into the condition $\alpha_{2}$ $+\alpha_{5}=0$ for the respective elements which can easily be tested statistically.

\footnotetext{
${ }^{7}$ The assumption that the impact of the policy change differs across regions can be tested statistically.
} 
We estimate equation (2) separately for those above and below the age of 14. For the latter, the parents' rather than own education will be relevant and, in addition, we can test for significant differences between orphans, "other relatives", i.e. children who are not direct offsprings of the household head, and own children on access to health services that might warrant attention by policy makers.

Incidence of sickness: As discussed earlier, the economic impact of the policy change will depend on how it affects the incidence of sickness in the overall population. To quantify this, we estimate a probit model

$$
S_{i t}=\alpha_{0}+\alpha_{1} \boldsymbol{X}_{i t}+\alpha_{2} \boldsymbol{H}_{i t}+\alpha_{3} T+\alpha_{4} \boldsymbol{H}_{i t} T+\alpha_{5} \boldsymbol{X}_{i t} T+\mu_{i t}
$$

where $S_{i t}$ takes the value of 1 if an individual reported being sick 30 days prior to the survey and 0 otherwise and most other variables are as defined before. A key difference to equation (2) is that this regression includes the whole population, not only the subset of individuals who reported to have suffered from sickness during the period. We expect asset ownership, adequate dwelling characteristics, and education to reduce the incidence of sickness. Again, the coefficient of key interest is $\alpha_{3}$, the net change in the propensity of sickness over time which we can interpret as the impact of the policy change, as well as the interaction of this variable with regional dummies and socio-economic characteristics. Also, as in the case of (2), we estimate separate regressions for adults and children aged 14 years and below. In the equation for children, we include a dummy that takes the value 1 if the child is an orphan and 0 otherwise in order to capture the impact of abolition of cost sharing on this group.

\subsection{Data and descriptive evidence}

To empirically implement the above regressions, we rely on two cross-sectional surveys, undertaken before and after the policy change, respectively. The first is the 1999/2000 Uganda National Household Survey (UNHS I), a representative survey of 10,696 households, fielded between August 1999 and September 2000. It is complemented by a sample of 9,711 households from the 2002/3 UNHS II who were interviewed between May 2002 and April 2003. Both surveys provide a rich source of information on individual and household characteristics, economic activity, asset endowments, and demand for (incidence of sickness in the previous 30 days) as well as utilization of health services, including some indication of potential constraints faced in doing so. At the facility level, we use the community module of the UNHS II which includes information on a range of indicators for quality of service provision including availability and prices of malarial drugs and antibiotics, the level of consultation fees and the number of opening hours- in public and private facilities ${ }^{8}$ both at the time of the survey and for

\footnotetext{
${ }^{8}$ For purposes of this paper, we define public hospitals as any health centre/facility/hospital financed out of public resources and managed by the government, either at the central or local government level. Private hospitals are defined as those health centres/facilities/hospitals that are financed by non-governmental organisations, private individuals and companies, including traditional health care establishments. In the discussion, we use the words 'hospital', 'health care centres' and 'health care institutions' inter-changeably to mean a health care facility, no matter its size. Our major concern is the type of ownership, which is distinguished as stated above. We also use the terms 'government hospital' and 'public hospital' interchangeably.
} 
1999/2000. The household and community information is complemented by administrative data gathered through a recently established Health Management Information Services (HMIS) administered by the $\mathrm{MOH}$. The data include monthly information on supply and use of a wide range of services by all public health facilities nationwide, aggregated to the district level. Although not all units report consistently over time, we were able to use about 2,000 data points for each of the different types of services, as discussed in more detail below.

Descriptive statistics relating to sickness and use of health services during the last 30 days by the more than 50,000 individuals included in each round of the household surveys, as reported in Table 2, highlight that ill health is indeed widespread and economically relevant. In the aggregate, almost 30\% of individuals (about $55 \%$ of them children and $45 \%$ adults) reported to have been sick, causing them to lose on average almost 8 work days per incident. Somewhat surprisingly, the data do not indicate a significant change in the incidence of sickness between the first and the second period. Also, disaggregation by quintile suggests little variation in the incidence of sickness or its duration across the income distribution.

This does not imply that the abolition of user fees did not have an impact: In fact, the share of those who used health services when sick increased by about $10 \%$ from $69 \%$ to $79 \%$. Possibly as a consequence, the number of workdays lost due to sickness by the average sick individual declined from 8.3 to 7 . At the same time, lack of comparability between the two surveys makes it difficult to get a clear picture of the change in market share by the public sector, causing us to rely on outcome indicators (e.g. incidence of rationing and workdays lost due to sickness) rather than use of public or private facilities the relevant indicator for analysis. ${ }^{9}$

Further support for an impact of the policy change at the descriptive level is provided by the fact that the share of sick households who reported to not have utilized health services due to high cost decreased from about $50 \%$ in 1999 to about $35 \%$ in 2002, a reduction that was particularly pronounced in the country's poorest region, the North, where, after the change, less than $30 \%$ reported to not have used health services due to the cost involved. ${ }^{10}$ Looking at changes over time across the income distribution illustrates that, indeed, the impact of the policy change seems to have been strongly pro-poor: The percentage increase of those who visited a hospital when sick was, with 12 and 14 percentage points, highest for those in the bottom two quintiles, compared to less than 6 percentage points for the top quintile. This is even more obvious if one considers the reasons for non-attendance: The share of those who quoted cost reasons for not attending a hospital when sick decreased by about 20 percentage points in the bottom three quintiles

\footnotetext{
${ }^{9}$ While the 2002/03 survey has a clear definition of the ownership of each health facility, the 1999/00 one gives type of ownership only for hospitals but not for clinics, dispensaries and health centres and drug shops which therefore had to be assigned to one type in 1999, which could explain the decline in the shares given that it may be difficult for the respondents to distinguish between the different definitions.

${ }^{10}$ Tables showing the regional disaggregation are available from the authors upon request.
} 
but by much less for the top quintile. This, together with the fact that the number of workdays lost to sickness show a marked decline, suggests that the policy change could have had a significant impact.

To provide a background for the subsequent regressions as well as the cost-benefit analysis based on them, table 3 summarizes household characteristics as well as household level spending on health services for both 2002 and 1999. In terms of descriptive statistics, one notes that the large majority of households (83-84\%) were from rural areas and point to some improvement in some socio-economic indicators such as education of the head (from 5 to 6 years), value of assets owned (from US $\$ 1,414$ to 1,504) and dwelling characteristics such as cement floors (from $22 \%$ to $26 \%$ ), availability of toilets (65\% to $75 \%$ ) and iron roofs ( $58 \%$ to $65 \%)$.

Before looking at the impact of the policy shift econometrically, it is important to assess the extent to which the abolition of user fees was not only decreed by political authorities but actually implemented on the ground. One way of doing so would be to compare spending by sick individuals on health care before and after the policy change. Unfortunately, since neither of the two surveys aimed to look specifically at health issues, the level of health spending is given only at the household rather than the individual level. Comparing the amounts spent on health by households with at least one sick person before and after the abolition of user charges can thus provide a first indication of the extent to which this policy was effective and will also be critical to make inferences on the overall costs and benefits of this measure. We note that, in the aggregate, the amount of monthly resources spent on health by households who had at least one person sick, increased slightly, from the equivalent of US\$4.92 to US\$5.00 although a t-test does not allow to reject the hypotheses of the two coefficients being equal. However, descriptive evidence points towards a statistically significant (at 1\%) decrease in health spending for the bottom two quintiles and (at $5 \%$ ) for the fourth quintile.

A second way to assess the impact of the policy change at a descriptive level is to draw on data from the $2002 / 3$ community survey which obtained information on the fees charged for a consultation and for different medicines, as well as the availability of these medicines in both periods (i.e. 2002/3 and retrospectively for 1999/2000), for private and public health facilities. Results from doing so, illustrated in table 4, suggest that the elimination of fees for consultation at government health units was indeed implemented quite uniformly: while almost $80 \%$ of units had charged for a consultation before the policy change, only $3 \%$ did so in the second period. Similarly, only about $4 \%$ of public health units charged for antibiotics and malaria drugs although a much lower share of $22 \%$ and $27 \%$, respectively, had charged for them in the initial period to begin with. Compared to the marked decrease in the number of units that 
charged for their services in public units, there was little change in observable quality indicators. ${ }^{11}$ Even though there was a slight decline in availability of antibiotics and malaria drugs in public hospitals bed capacity did actually increase slightly and there is no change in the number of hours per day during which the facility was open. Comparing public to private hospitals clearly illustrates that the policy change was limited to the former. As table 4 illustrates, no such changes are visible in private facilities almost all of which charged for medicines both before and after the abolition of user charges, with slightly more than half also charging for consultations.

Taking these figures together allows us to obtain an estimate of the reduction of revenue to the public system through elimination of user charges which amounts to about US\$3.4 million per year. ${ }^{12}$ This was more than compensated by an increase in the health budget of more than US\$20 million. A key element of the econometric analysis to be performed below is to obtain an estimate of the benefits the policy shift provided to individuals that would allow to compute a social cost-benefit ratio.

\section{Econometric results}

While administrative data point toward a significant expansion in the provision of services, they do not allow us to make inferences on who in the population benefited and how the better provision of services translated into improved outcomes. Analysis of household level data to provide insight into these questions shows that there was a clear reduction of rationing, especially for children; there is no appreciable impact on the choice of provider between public and private establishments, and morbidity was reduced in a pro-poor way as a result of the policy change.

\subsection{Administrative data}

Regressions using administrative data as reported in table 5, suggest significant, though regionally uneven, increases in the provision of services by health units following the abolition of user fees. In particular, we find that, on average, the number of new cases treated by the health centres increased by $18.5 \%$ for under 5 -year olds and by $31 \%$ for individuals of the age of 5 and above while the number of referrals increased by $26 \%$. The increase was particularly pronounced in the West (50\% for adults, $25 \%$ for children) and the East (42\% for adults and 30\% for children) but not at all visible in the North. Provision of simple services such as weighing and vitamin A supplementation for children increased everywhere (by $38 \%$ for weighing and $61 \%$ for supplements ), one observes significant differences in this

\footnotetext{
${ }^{11}$ In interpreting these figures, one should note that responses were given by officials who may have an interest in overstating the quality of service provision and that a cross-check with information from households who actually needed such medicines would be desirable in future rounds of the survey.
} 
increase across regions. Similar strong increases of between $12 \%$ and $34 \%$ emerge for antenatal and postnatal cases as well as the number of deliveries handled at the unit, something that was associated with a decrease in the number of deliveries handled by traditional birth assistants at least in some regions. However, more detailed exploration of the issue using household data is needed to explore whether the strong regional differences emerging from administrative data are just a reflection of differential rates of reporting or associated with conditions of ongoing fighting or shortages in technical equipment in the North, the extent to which they accrue to the poor, and whether they actually translate into an impact on individuals' health status.

\subsection{Rationing for those suffering from sickness}

Probit regressions to explore the extent to which the abolition of user fees helped to reduce rationing for people who were sick, i.e. them not being able to access health services because of high costs or long distances, are reported in table 6, separately for adults (columns 2 and 3) and children (columns 4 and 5). All the coefficients reported are marginal probabilities. As discussed earlier, the net effect of the policy change is the coefficient on the year dummy or its interaction with various socio-economic attributes. We also note that there is no gender bias as indicated by the lack of significance of the coefficient on the female dummy.

Holding constant for other characteristics, the elimination of user fees is estimated to have resulted in a reduction of $8 \%$ and $11.5 \%$ for adults and children respectively in the probability of being rationed. Not surprisingly, the probability of being rationed decreases in wealth, as approximated by the total value of assets held by the household, and also (for adults) in household size. It is lower by about $5 \%$ for cases of malaria and, in the case of children, also for intensive sickness, defined as including measles as well as cases of HIV/AIDS, hypertension and accidents. Distance from a hospital is not significant for adults but increases the probability of being rationed for children. This probability is also higher (by about $6 \%$ in rural areas) and increases with education as well as the households having a cement floor and a pit latrine, two attributes that reflect higher standards of hygiene as well as wealth and is convex in age for adults and concave for children. Regional differences are pronounced, with the probability of rationing being lowest in the West and highest in the East for adults as well as children.

In addition to the reduction in the probability of rationing over time which can be interpreted as a direct measure of the impact of the policy change, the coefficients on the year dummy's interaction with other socio-economic variables can provide insights as to the extent to which the policy change favoured (or put at a disadvantage) some specific groups in the population. We first interpret the findings for adults and

\footnotetext{
${ }^{12}$ Each consultation provided income of USh 500 to establishments (about $80 \%$ of the total) who collected such fees before the policy change. In each month $27 \%$ of individuals in the population got sick (of which $70 \%$ visited a private hospital and $30 \%$ public facilities). The exchange rate
} 
then for children. For the former, the positive sign and significance (at 10\%) of the interaction with asset ownership implies that, following the policy change, the health system has become somewhat less wealth biased. At the same time, the $\chi^{2}$ test for $\alpha_{2}+\beta_{2}=0$ reported in the bottom of the table clearly rejects the hypothesis that, under the new system, wealth does no longer matter. Also, the reforms did not help to reduce the structural disadvantage that had characterized rural areas in the initial period. Finally, interacting regional dummies with the year dummy results in loss of significance of the overall year dummy, implying that, rather than having been uniform nationally, the impact of the policy change was particularly large in the East and the West but not significantly different from zero in the North and the Centre.

Turning toward children, we find that, for this group, the impact of the policy change was not only larger in the aggregate but also more pronounced for different sub-groups. The most interesting finding is that, contrary to what was observed for adults, the initial wealth bias of the health system which was equal in magnitude to what was observed for adults, was completely eliminated in the second period..$^{13}$ In addition, the bias against rural areas that had prevailed in the first period was significantly reduced, though not completely eliminated, in the second. While we can not find any indication that orphans have been more likely to be rationed out of the use of health services, we find that "other relatives", i.e. children who are not physical offsprings of the head of household, were significantly more likely to be rationed in the first period but that this effect had been eliminated after the policy change (as evidenced by the $\chi^{2}$ test for $\alpha_{3}+$ $\beta_{3}$ ). Finally, even though the hypothesis of equality of the impact of the reforms across regions is rejected, we find that in the North and the West, the point estimate of the reduction due to the policy reforms is much higher (column 5) than in the regression for adults.

\subsection{Health outcomes}

The loss of income caused by sickness has generally been viewed as being the economically most immediate and important impact of ill-health and can therefore be used to assess the benefits from the policy on abolishing user charges as well as their incidence across different groups. Regressions to identify determinants of sickness (table 7), with right hand side variables parallel to those used earlier in the rationing models to allow comparability, illustrate that the reform did indeed affect health outcomes. ${ }^{14}$

For adults, a surprising finding is that the probability of falling sick did not decrease in the aggregate (column 2). However, even though the time dummy by itself is insignificant, i.e. we have to reject that the

\footnotetext{
used is USh 1900 to one US\$.

${ }^{13}$ Note that the $\chi^{2}$ test does not allow to reject the hypothesis that $\alpha_{2}+\beta_{2}=0$, implying that after the abolition of user fees, parents' wealth no longer has a significant impact on the extent to which children are rationed out from access to health services.

${ }^{14}$ Results from tobit regressions using the number of days lost due to sickness are very similar to those for the probit regressions and therefore not reported separately and can be obtained from the authors upon request.
} 
policy change had an impact that was uniform across different types of households, this does not mean that it was ineffectual. First, for all regions except the Centre, a strong reduction of the propensity to fall sick is indeed confirmed (column 3). Moreover, in addition, in 1999/2000 there was a strong wealth bias whereby the probability of being sick declined with the value of household wealth. As the lower panel shows, we are unable to reject that $\alpha_{1}+\beta_{1}=0$, implying that the wealth bias was completely eliminated in the second period. While the house having a cement floor and a pit latrine reduced the propensity to fall sick, there was neither a gender bias nor a bias against rural areas. Higher age did increase the probability of falling sick linearly while education and household size decreased it and the East (as well as to some extent the North) are shown to be subject to a particularly high disease pressure. All of this suggests that the abolition of user fees reduced the propensity of falling sick for specific groups and was pro-poor in the sense that the initial wealth bias was eliminated after the reforms.

Results for children are not only consistent with this finding but, in line with the more pronounced impact of the reforms on the incidence of rationing found earlier, even stronger than for adults. We estimate that the propensity for children to fall sick decreased by $4.4 \%$ in the aggregate. Moreover, as in the case for adults, the initial wealth bias with respect to health outcomes has been eliminated due to the reforms. Sanitary conditions at the household level and the household head's education have a less pronounced impact on children's health than for adults. Even though a more detailed study may be needed, a possible reason for a more pronounced impact of the reforms on children than on adults is that for the former it is possible to have more standard treatment, implying that quality of service provision may be less relevant.

However, given the overall rather positive impact of the reforms on children's health, it is worth noting that, in contrast to children ("other relatives") who are not the direct offspring of the household head and who are actually estimated to be less likely to fall sick (though this did not change over time), orphans are estimated to have been marginally more likely to fall sick in the initial period. This disadvantage has actually worsened over time; as can be seen in column 5, the regression suggests that after the reforms orphans were $3.8 \%$ more likely to be afflicted by sickness. While this suggests that countervailing factors may have been at work which more than compensated for the benefits accruing through the elimination of user fees, it reinforces the finding that the impact of the abolition of fees has not been uniform across the population and would imply that specific measures of assistance to groups such as orphans who are not well served by the present system may need to be contemplated.

\subsection{Towards an assessment of the costs and benefits from the health sector reforms}

Although they provide interesting insights in their own right, the econometric results discussed above can also be used to provide a very rough estimate of the benefits from the reforms that can be compared to the 
foregone revenue, as computed earlier. ${ }^{15}$ To do so, we use the regressions reported in table 7 to predict, for each individual in the sample, the change in the expected probability of sickness due to the policy change as approximated by the time dummy and its various interactions. Multiplying the change in the probability of falling sick with the mean expected length of sickness and the average unskilled wage rate for adults (or one fourth of this rate for children) yields a lower bound on the expected saving of income that would otherwise be foregone due to sickness which can be interpreted as the economic benefit of the policy change. Table 8 illustrates the results, in terms of change in the probability of falling sick, the annualized benefits per individual (in USh), and the expected overall benefit in million US\$, all separated for adults and children. To illustrate the distributional aspect of the policy change, we complement evidence on the aggregate effect (in row 6) with the predicted impact for the quintiles of the wealth distribution (rows 1-5). Two results are particularly noteworthy.

First, the overall impact is not only quite significant but also compares favorably to the foregone revenue from the measure. The probability of falling sick decreased by $1.5 \%$ for adults and $3 \%$ for children. In the aggregate, the minimum gains in terms of savings of foregone wages for adults alone amount to almost US\$9 million, a figure that is more than double of the shortfall in revenue caused by the policy change as discussed above. Thus, even though the much larger benefit from the reduction in the propensity to fall sick for children is less readily quantified, it appears that the measure did provide social benefits that were commensurate to the cost in terms of foregone revenue.

A second finding of interest is that, as illustrated by the quintile-wise figures, the benefits from the policy change did accrue largely to the poor. In fact, for adults almost half the total benefit accrued to the bottom quintile (column 5) and more than two thirds of the benefits, according to our estimates, benefited those in the bottom two quintiles. This is consistent with anecdotal evidence which highlights that those who could afford it often switched to private facilities and suggests that, in Uganda, the abolition of user fees was more effective in reaching the poor than the policy of exemptions which was meant to achieve this goal earlier. A similarly pro-poor picture emerges for children. While this does not imply that all groups benefited equally - to the contrary our results for orphans show that specific groups may still require special attention - it does conform with the notion that even relatively modest fees for health services operated as a significant deterrent to the poor who were able to derive significant benefits from their elimination, at least in the short run. Of course, in order to maintain these gains in the longer term, it will be critical to ensure continuing or even improving quality of the services available at public health facilities, something that continues to pose a challenge.

\footnotetext{
${ }^{15}$ It would be of great interest to use some of the information used here as an input into a more detailed cost-benefit analysis of the policy changes. Doing so would, however, require more information especially on the cost side and clearly transcends the scope of this study.
} 


\section{Conclusion and policy implications}

While there has been considerable debate on the impact of user fees for both the use of health services and the incidence of sickness in the population, few studies have utilized micro-data from before and after a significant policy intervention to assess this impact. The abolition of user fees in Uganda (in March 2001), together with the availability of two large household data sets from before and after the policy change, respectively, allows us to examine the impact of this policy on the demand for health care and on the incidence of sickness - and the economic impact of being sick.

In line with administrative data that point toward significant, though regionally differentiated, increases in the delivery of services, we find that the abolition of user fees reduced the incidence of rationing, particularly by the poor. While the impact on the choice of health facilities was less pronounced, there was a significant impact on the probability of being sick, which was greater for children than for adults. This provided particular benefits to the poor by eliminating, among others, asset bias in the incidence of sickness. In fact, using the regressions to provide a rough initial estimate of the value of the time saved as a result of the policy change suggests that the social benefits exceed the likely amount of revenue foregone and the significant economic benefits were concentrated among the poor. Although this does not imply that the abolition of user fees solved all the problems affecting the health sector in Uganda, it is not inconsistent with the notion that the monetary cost of treatment did constitute a barrier for the poor.

Our results highlight that the abolition of fees improved access as well as outcomes, something that is likely to be at least in part attributable to the increase in health sector funding, as well as measures to improve the supply of health services that were contemporaneous to the elimination of user fees. This illustrates the potential of an approach that removes obstacles to supply health services in a coordinated manner. Maintenance of these gains, which would eventually help Uganda to improve health sector performance, will require continued attention to the quality of service provision in the public sector. This will require the establishment of a system to continuously monitor, publicize, and reward the quality of service delivery and client satisfaction in different regions and health units. Having addressed the issue of access in a radical fashion, the challenge facing Uganda is to devise mechanisms that would provide both market and non-market incentives to maintain and improve the quality of health care. 
Table 1: Health indicators for Uganda and selected other African countries

\begin{tabular}{|c|c|c|c|c|c|c|c|c|c|}
\hline \multirow[b]{2}{*}{ Country/year } & \multirow{2}{*}{$\begin{array}{c}\text { Infant } \\
\text { mortality } \\
<1 \text { year } \\
\end{array}$} & \multirow{2}{*}{$\begin{array}{l}\text { Diarrhoea } \\
\text { prevalence } \\
<6 \text { months }\end{array}$} & \multicolumn{2}{|c|}{ Nutritional status } & \multirow[t]{2}{*}{$\begin{array}{l}\text { Antenatal } \\
\text { care }\end{array}$} & \multicolumn{4}{|c|}{$\begin{array}{l}\text { Vaccination coverage during first year of life } \\
\text { For children aged } 1-2 \text { yrs }\end{array}$} \\
\hline & & & HAZ & WHZ & & BCG & DPT3 & Polio3 & Measles \\
\hline \multicolumn{10}{|l|}{ Uganda } \\
\hline Uganda 1988 & 98.3 & 26 & 39.4 & 1.2 & 76.1 & 41.4 & 20.6 & 21.3 & 24.4 \\
\hline Uganda 1995 & 81.3 & 17.7 & 35.8 & 5.4 & 81.6 & 79.4 & 54.5 & 52.6 & 45.2 \\
\hline Uganda 2000/01 & 88.3 & 17.8 & 34 & 5.1 & 83.8 & 75.0 & 42.0 & 49.6 & 42.3 \\
\hline \multicolumn{10}{|l|}{ Other countries } \\
\hline Burkina Faso 1992/93 & 93.7 & 15.7 & 30.6 & 16.7 & 57.1 & 80.2 & 32.6 & 32.8 & 37.1 \\
\hline Burkina Faso 1998/99 & 105.3 & 14.4 & 34.9 & 16.7 & 60.7 & 69.9 & 34.8 & 36.0 & 32.1 \\
\hline Cote d'Ivoire 1994 & 88.5 & 11.6 & 24.4 & 8.3 & 79.1 & 72.8 & 41.0 & 45.1 & 37.7 \\
\hline Cote d'Ivoire 98/99 & 112.2 & 10.3 & 21.3 & 9.6 & 78.5 & 82.0 & 54.9 & 54.6 & 51.3 \\
\hline Ghana 1988 & 77.2 & 16.3 & 31.1 & 7.2 & 55.7 & 33.5 & 19.1 & 18.4 & 19.4 \\
\hline Ghana 1993 & 66.4 & 14.2 & 25.9 & 11.3 & 59.2 & 80.8 & 57.1 & 57.3 & 50.6 \\
\hline Ghana 1998 & 56.7 & 13.6 & 19.2 & 13 & 62.8 & 85.9 & 67.6 & 67.1 & 60.9 \\
\hline Kenya 1989 & 60.7 & 17.1 & - & - & 48.9 & 58.0 & 52.7 & 54.3 & 41.7 \\
\hline Kenya 1993 & 61.7 & 13.5 & 29.0 & 4.6 & 71.0 & 94.7 & 85.4 & 84.1 & 76.3 \\
\hline Kenya 1998 & 73.7 & 11.9 & 33 & 6.1 & 64.1 & 94.0 & 76.3 & 71.6 & 70.7 \\
\hline Nigeria 1990 & 87.4 & 10.9 & 37.9 & 8.7 & 23.5 & 50.1 & 28.5 & 28.6 & 30.4 \\
\hline Nigeria 1999 & 75 & 8.2 & 45.5 & 12.4 & 38.9 & 52.0 & 24.8 & 23.0 & 32.1 \\
\hline Zimbabwe 1988 & 49.1 & 15.1 & 27.4 & 1.6 & 72.9 & 74.9 & 65.3 & 65.2 & 62.7 \\
\hline Zimbabwe 1994 & 52.8 & 13.8 & 21.4 & 5.5 & 72.2 & 94.6 & 80.4 & 80.3 & 73.9 \\
\hline Zimbabwe 1999 & 65 & 6.1 & 26.4 & 7.1 & 80.5 & 87.4 & 77.5 & 65.5 & 81.4 \\
\hline
\end{tabular}

Sources: Own computation from various DHS Surveys (www.measuredhs.com/data/indicators).

Note: Infant mortality is measured in terms of deaths per 1,000 live births For nutritional status, HAZ refers to height-for-age (stunting) and WAZ to weight-for-age (wasting). In the different vaccinations, BCG implies vaccination against tuberculosis and DPT against three Diphtheria, Pertussis (whooping cough) and Tetanus. As for the latter as well as for Polio, three doses are required to ensure full coverage, we report only the share of children who received all three doses. 
Table 2: Incidence of sickness and use health services by the sick, Uganda 1999 and 2002

\begin{tabular}{|c|c|c|c|c|c|c|}
\hline & & & & 2002 & & \\
\hline & All & $1^{\text {st }}$ quintile & $2^{\text {nd }}$ & $3^{\text {rd }}$ & $4^{\text {th }}$ & $5^{\text {th }}$ quintile \\
\hline Sick in previous 30 days & 28.22 & 26.28 & 27.45 & 28.56 & 30.99 & 28.73 \\
\hline Children & 54.66 & 56.60 & 57.39 & 57.20 & 53.60 & 46.11 \\
\hline Adults & 45.34 & 43.40 & 42.61 & 42.80 & 46.40 & 53.89 \\
\hline Workdays lost & 7.27 & 7.45 & 7.27 & 7.19 & 7.17 & 7.26 \\
\hline Visited hospital when sick & 78.72 & 70.07 & 78.46 & 80.51 & 81.73 & 85.26 \\
\hline Government hospital & 30.15 & 44.72 & 32.72 & 27.63 & 24.74 & 19.41 \\
\hline Private hospital & 69.85 & 55.28 & 67.28 & 72.37 & 75.26 & 80.59 \\
\hline Did not go to hospital when sick & 21.28 & 29.93 & 21.54 & 19.49 & 18.27 & 14.74 \\
\hline Sickness mild & 38.93 & 31.35 & 31.52 & 42.64 & 46.86 & 59.93 \\
\hline Long distance & 26.14 & 29.41 & 29.81 & 25.56 & 22.01 & 15.56 \\
\hline High cost & 34.92 & 39.24 & 38.67 & 31.80 & 31.13 & 24.51 \\
\hline \multirow[t]{3}{*}{ Observations } & 50,256 & 10,067 & 10,043 & 10,048 & 10,052 & 10,046 \\
\hline & \multicolumn{6}{|c|}{1999} \\
\hline & All & $1^{\text {st }}$ quintile & $2^{\text {nd }}$ & $3^{\text {rd }}$ & $4^{\text {th }}$ & $5^{\text {th }}$ quintile \\
\hline Sick in previous 30 days & 27.49 & 25.38 & 27.67 & 27.65 & 29.29 & 27.94 \\
\hline Children & 52.47 & 58.36 & 54.89 & 53.99 & 48.61 & 45.73 \\
\hline Adults & 47.53 & 41.64 & 45.11 & 46.01 & 51.39 & 54.27 \\
\hline Workdays lost & 8.30 & 8.24 & 8.18 & 8.17 & 8.66 & 8.25 \\
\hline Visited hospital when sick & 68.60 & 57.63 & 64.80 & 68.35 & 73.99 & 79.59 \\
\hline Government hospital & 33.86 & 42.80 & 35.89 & 36.09 & 31.24 & 25.33 \\
\hline Private hospital & 66.14 & 57.20 & 64.11 & 63.91 & 68.76 & 74.67 \\
\hline Did not go to hospital when sick & 31.40 & 42.37 & 35.20 & 31.65 & 26.01 & 20.41 \\
\hline Sickness mild & 34.52 & 24.34 & 30.70 & 35.80 & 39.40 & 57.18 \\
\hline Long distance & 15.92 & 17.95 & 17.64 & 14.70 & 16.52 & 9.00 \\
\hline High cost & 49.57 & 57.71 & 51.66 & 49.50 & 44.08 & 33.82 \\
\hline Observations & 57,058 & 11,413 & 11,412 & 11,415 & 11,412 & 11,406 \\
\hline
\end{tabular}

Source: Own calculation from UNHS 1999 and preliminary data for UNHS 2002 
Table 3: Summary of household characteristics in Uganda, 1999 and 2002

\begin{tabular}{|c|c|c|c|c|c|c|c|c|c|c|}
\hline & \multirow[b]{2}{*}{ All Uganda } & \multicolumn{4}{|c|}{ Regions } & \multicolumn{5}{|c|}{ Quintiles } \\
\hline & & Central & East & North & $\begin{array}{l}\text { West } \\
2002\end{array}$ & 1 st & 2nd & 3rd & 4th & 5 th \\
\hline Head's age (years) & 39.12 & 38.74 & 39.36 & 39.39 & 39.13 & 44.21 & 41.01 & 38.64 & 35.81 & 34.42 \\
\hline Female head (\%) & 24.53 & 27.08 & 21.34 & 30.21 & 20.39 & 25.84 & 23.16 & 21.80 & 22.53 & 29.20 \\
\hline Head's education (years) & 6.11 & 7.18 & 5.73 & 5.11 & 5.91 & 3.80 & 5.22 & 5.90 & 7.41 & 8.91 \\
\hline Maximum education in household & 8.03 & 9.12 & 7.77 & 6.46 & 8.08 & 5.85 & 7.30 & 8.01 & 9.03 & 10.56 \\
\hline Household size & 5.23 & 4.88 & 5.58 & 5.19 & 5.36 & 6.23 & 5.77 & 5.43 & 4.66 & 3.77 \\
\hline Monthly consumption expenditure (US\$, 2002) & 85.27 & 123.55 & 71.77 & 46.82 & 79.42 & 34.21 & 54.26 & 72.49 & 94.21 & 187.31 \\
\hline Monthly expenditure on health (US\$, 2002) & 5.00 & 5.74 & 4.85 & 2.75 & 5.99 & 1.49 & 2.55 & 4.38 & 6.17 & 10.40 \\
\hline Value of assets (US\$, 2002) & 1,528 & 1,867 & 1,327 & 836 & 1,825 & 833 & 1,206 & 1,520 & 1,771 & 2,519 \\
\hline Iron sheet roof & 64.42 & 88.36 & 54.72 & 14.10 & 81.78 & 38.14 & 56.03 & 68.91 & 76.66 & 89.77 \\
\hline Cement floor & 26.04 & 49.22 & 15.66 & 7.12 & 21.54 & 4.31 & 10.23 & 22.86 & 34.43 & 65.74 \\
\hline Toilet facility & 74.96 & 80.64 & 65.03 & 58.32 & 90.62 & 57.40 & 72.25 & 77.64 & 84.74 & 87.35 \\
\hline Rural households & 83.27 & 66.92 & 90.02 & 92.11 & 90.40 & 96.55 & 94.47 & 88.61 & 80.03 & 51.99 \\
\hline \multirow[t]{2}{*}{ Observations } & 9,711 & 2,831 & 2,675 & 1,730 & 2,475 & 1,898 & 1,897 & 1,897 & 1,897 & 1,897 \\
\hline & \multicolumn{10}{|c|}{1999} \\
\hline Head's age (years) & 42.88 & 41.89 & 43.25 & 42.47 & 44.11 & 47.34 & 45.26 & 42.78 & 40.08 & 36.81 \\
\hline Female head (\%) & 25.18 & 27.65 & 21.57 & 32.24 & 20.38 & 27.21 & 23.35 & 23.38 & 24.58 & 27.63 \\
\hline Head's education (years) & 5.11 & 6.09 & 5.09 & 4.04 & 4.67 & 3.13 & 4.42 & 4.96 & 5.88 & 8.10 \\
\hline Maximum education in household & 7.10 & 8.05 & 7.11 & 5.53 & 7.06 & 5.10 & 6.58 & 7.09 & 7.85 & 9.75 \\
\hline Household size & 5.45 & 5.01 & 5.56 & 5.60 & 5.80 & 6.37 & 6.07 & 5.51 & 4.91 & 3.89 \\
\hline Monthly consumption expenditure (US\$, 2002) & 84.30 & 119.40 & 71.96 & 43.54 & 83.11 & 34.81 & 57.17 & 73.50 & 96.16 & 188.90 \\
\hline Monthly expenditure on health (US\$, 2002) & 4.92 & 6.46 & 3.63 & 3.06 & 6.26 & 1.71 & 3.13 & 4.41 & 7.02 & 10.87 \\
\hline Value of assets (US\$, 2002) & 1,445 & 2,336 & 1,047 & 361 & 1,547 & 495 & 882 & 1,170 & 1,980 & 3,245 \\
\hline Iron sheet roof & 58.24 & 84.45 & 48.95 & 9.10 & 72.04 & 29.88 & 53.85 & 61.10 & 70.74 & 86.19 \\
\hline Cement floor & 21.87 & 42.13 & 15.38 & 4.61 & 15.60 & 2.79 & 8.75 & 16.15 & 31.53 & 61.82 \\
\hline Toilet facility & 65.77 & 76.74 & 55.02 & 42.21 & 81.39 & 47.02 & 64.15 & 69.54 & 76.69 & 77.26 \\
\hline Rural households & 84.41 & 67.25 & 90.14 & 94.47 & 93.03 & 97.81 & 95.24 & 91.19 & 81.44 & 46.57 \\
\hline Observations & 10,695 & 3,110 & 2,865 & 1,801 & 2,919 & 2,082 & 2,081 & 2,081 & 2,081 & 2,081 \\
\hline
\end{tabular}

Source: Own calculation from UNHS 1999 and 2002. 
Table 4: Status of health facilities before and after abolition of user fees

\begin{tabular}{|c|c|c|c|c|c|}
\hline \multirow[b]{2}{*}{ Variable } & \multicolumn{3}{|c|}{ Government hospitals } & \multicolumn{2}{|c|}{ Private hospitals } \\
\hline & Before & \multicolumn{2}{|c|}{ After } & Before & After \\
\hline \multicolumn{6}{|c|}{ Proportion of communities in which patients had to pay for: } \\
\hline Consultation $(\%)$ & 79.10 & 3.36 & & 52.43 & 52.43 \\
\hline Antibiotics (\%) & 22.37 & 4.11 & *** & 95.24 & 96.60 \\
\hline Malarial drugs $(\%)$ & 27.31 & 3.87 & *** & 95.66 & 96.75 \\
\hline \multicolumn{6}{|c|}{ Availability of medicine and facilities } \\
\hline Antibiotics $(\%)$ & 97.80 & 93.39 & $* * *$ & 94.09 & 94.20 \\
\hline Malarial drugs (\%) & $99.45^{* * *}$ & 96.56 & $* * *$ & 99.39 & 99.46 \\
\hline Bed capacity (\%) & 64.06 & 76.59 & & 24.77 & 21.63 \\
\hline Hours open per day & 18.40 & 18.12 & & 16.84 & 16.23 \\
\hline Observations & 676 & 696 & & 434 & 463 \\
\hline
\end{tabular}

Source: Own calculation from the 2002 UNHS community survey.

*Significant at $10 \%$; * Significant at 5\%; ***Significant at $1 \%$.

Table 5: Impact of policy change based on administrative data

\begin{tabular}{|c|c|c|c|c|c|c|}
\hline & \multirow[t]{2}{*}{ All Uganda } & \multicolumn{4}{|c|}{ Region } & \multirow[t]{2}{*}{ Observations } \\
\hline & & Central & East & North & West & \\
\hline \multicolumn{7}{|l|}{ New cases and referrals } \\
\hline Under 5 years) & $\begin{array}{l}0.185^{* * *} \\
(5.83)\end{array}$ & $\begin{array}{l}0.263 * * * \\
(5.49)\end{array}$ & $\begin{array}{l}0.301 * * * \\
(6.36)\end{array}$ & $\begin{array}{l}-0.107 \\
(1.29)\end{array}$ & $\begin{array}{l}0.253 * * * \\
(4.11)\end{array}$ & 1,902 \\
\hline 5 years and above & $\begin{array}{c}0.309 * * * \\
(9.59)\end{array}$ & $\begin{array}{l}0.348 * * * \\
(7.78)\end{array}$ & $\begin{array}{l}0.429 * * * \\
(7.60)\end{array}$ & $\begin{array}{l}-0.031 \\
(0.33)\end{array}$ & $\begin{array}{c}0.494 * * * \\
(10.39)\end{array}$ & 1,903 \\
\hline Referrals & $\begin{array}{l}0.259 * * * \\
(5.23)\end{array}$ & $\begin{array}{c}0.336 * * * \\
(3.30)\end{array}$ & $\begin{array}{c}0.359 * * * \\
(4.00)\end{array}$ & $\begin{array}{l}0.029 \\
(0.24)\end{array}$ & $\begin{array}{l}0.439 * * * \\
(5.01)\end{array}$ & 1,878 \\
\hline \multicolumn{7}{|l|}{ Ante- and perinatal cases } \\
\hline New antenatal cases & $\begin{array}{l}0.122 * * * \\
(3.36)\end{array}$ & $\begin{array}{l}0.018 \\
(0.22)\end{array}$ & $\begin{array}{l}0.241^{* * *} \\
(3.16)\end{array}$ & $\begin{array}{l}(0.021 \\
(0.27)\end{array}$ & $\begin{array}{l}0.270 * * * \\
(4.19)\end{array}$ & 1,746 \\
\hline Re-attendances/referrals & $\begin{array}{c}0.165 * * * \\
(5.37)\end{array}$ & $\begin{array}{c}0.248 * * * \\
(3.09)\end{array}$ & $\begin{array}{c}0.520 * * * \\
(6.52)\end{array}$ & $\begin{array}{c}0.273 * * \\
(2.35)\end{array}$ & $\begin{array}{c}0.413 * * * \\
(3.71)\end{array}$ & 1,815 \\
\hline Deliveries at unit & $\begin{array}{l}0.278 * * * \\
(7.98)\end{array}$ & $\begin{array}{l}0.261^{* * *} \\
(3.35)\end{array}$ & $\begin{array}{l}0.286^{* * *} \\
(5.15)\end{array}$ & $\begin{array}{l}0.250 * * * \\
(3.25)\end{array}$ & $\begin{array}{l}0.459 * * * \\
(6.76)\end{array}$ & 1,884 \\
\hline $\begin{array}{l}\text { Deliveries handled by } \\
\text { traditional birth assistants }\end{array}$ & $\begin{array}{l}-0.156^{* * *} \\
(3.66)\end{array}$ & $\begin{array}{c}-0.196^{*} \\
(1.97)\end{array}$ & $\begin{array}{c}-0.128^{*} \\
(1.67)\end{array}$ & $\begin{array}{l}-0.088 \\
(0.88)\end{array}$ & $\begin{array}{l}0.027 \\
(0.31)\end{array}$ & 1,777 \\
\hline Post natal cases & $\begin{array}{c}0.341 * * * \\
(7.13)\end{array}$ & $\begin{array}{l}0.057 \\
(0.89)\end{array}$ & $\begin{array}{l}0.304 * * * \\
(6.05)\end{array}$ & $\begin{array}{l}0.061 \\
(0.89)\end{array}$ & $\begin{array}{l}0.252 \\
(4.28)\end{array}$ & 1,724 \\
\hline \multicolumn{7}{|l|}{ Children's care } \\
\hline Total weighed & $\begin{array}{l}0.382 * * * \\
(7.44)\end{array}$ & $\begin{array}{l}0.681^{* * *} \\
(5.34)\end{array}$ & $\begin{array}{l}0.352 * * * \\
(4.13)\end{array}$ & $\begin{array}{c}0.308^{* *} \\
(2.22)\end{array}$ & $\begin{array}{c}0.337 * * * \\
(4.21)\end{array}$ & 1,667 \\
\hline Vitamin A supplementations & $\begin{array}{c}0.613 * * * \\
(12.28) \\
\end{array}$ & $\begin{array}{c}0.744 * * * \\
(7.45) \\
\end{array}$ & $\begin{array}{c}0.785^{* * *} \\
(9.10)\end{array}$ & $\begin{array}{c}0.320^{* *} \\
(2.51) \\
\end{array}$ & $\begin{array}{c}0.787 * * * \\
(9.15) \\
\end{array}$ & 1,700 \\
\hline
\end{tabular}

$\mathrm{t}$-statistics in parenthesis.

** significant at the $5 \%$ level; *** significant at the $1 \%$ level. 
Table 6: Determinants of being rationed conditional on being sick

\begin{tabular}{|c|c|c|c|c|}
\hline & (1) & (2) & (3) & (4) \\
\hline & \multicolumn{2}{|c|}{ Adults } & \multicolumn{2}{|c|}{ Children } \\
\hline \multirow[t]{2}{*}{ Year dummy, 2002 = 1} & $-0.079 * * *$ & -0.035 & $-0.115 * * *$ & -0.023 \\
\hline & $(2.82)$ & (1.13) & (4.34) & $(0.78)$ \\
\hline \multirow[t]{2}{*}{ Total asset value $(\log )\left[\alpha_{1}\right]$} & $-0.016^{* * *}$ & $-0.017 * * *$ & $-0.018 * * *$ & $-0.017 * * *$ \\
\hline & $(5.63)$ & $(5.79)$ & (6.69) & $(6.05)$ \\
\hline \multirow[t]{2}{*}{ Assets*year $\left[\beta_{1}\right]$} & $0.007^{*}$ & $0.008^{*}$ & $0.019 * * *$ & $0.017 * * *$ \\
\hline & $(1.67)$ & $(1.96)$ & $(5.08)$ & $(4.51)$ \\
\hline \multirow[t]{2}{*}{ Cement floor } & $-0.040 * * *$ & $-0.041 * * *$ & $-0.041 * * *$ & $-0.044 * * *$ \\
\hline & (4.59) & (4.82) & $(5.56)$ & $(6.01)$ \\
\hline \multirow[t]{2}{*}{ Pit latrine } & $-0.025 * * *$ & $-0.025 * * *$ & $-0.033 * * *$ & $-0.032 * * *$ \\
\hline & $(3.65)$ & (3.67) & $(5.67)$ & $(5.57)$ \\
\hline \multirow[t]{2}{*}{ Distance to hospital } & -0.000 & -0.000 & $0.002 * * *$ & $0.002 * * *$ \\
\hline & $(1.34)$ & $(0.97)$ & $(6.71)$ & $(7.01)$ \\
\hline \multirow[t]{2}{*}{ Age in years } & $-0.003 * * *$ & $-0.003 * * *$ & $0.013 * * *$ & $0.013 * * *$ \\
\hline & $(3.80)$ & (3.61) & $(6.19)$ & $(6.16)$ \\
\hline \multirow[t]{2}{*}{ Age squared } & $0.005 * * *$ & $0.005 * * *$ & $-0.062 * * *$ & $-0.062 * * *$ \\
\hline & $(6.25)$ & (6.07) & (3.97) & (3.99) \\
\hline \multirow[t]{2}{*}{ Female } & -0.000 & -0.000 & -0.003 & -0.004 \\
\hline & $(0.01)$ & $(0.05)$ & $(0.55)$ & $(0.82)$ \\
\hline \multirow[t]{2}{*}{ Education } & $-0.006 * * *$ & $-0.006 * * *$ & $-0.004 * * *$ & $-0.004 * * *$ \\
\hline & (7.77) & (7.74) & $(5.50)$ & (5.49) \\
\hline \multirow[t]{2}{*}{ Orphan $\left[\alpha_{2}\right]$} & & & 0.006 & -0.005 \\
\hline & & & $(0.76)$ & $(0.43)$ \\
\hline \multirow{2}{*}{ Orphan*year $\left[\beta_{2}\right]$} & & & & 0.024 \\
\hline & & & & (1.39) \\
\hline \multirow[t]{2}{*}{ Other relative $\left[\alpha_{3}\right]$} & & & $0.018 * *$ & $0.032 * * *$ \\
\hline & & & $(2.46)$ & $(3.37)$ \\
\hline Other relative*year $\left[\beta_{3}\right]$ & & & & $-0.027 * *$ \\
\hline & & & & $(2.09)$ \\
\hline Household size & $-0.003 * * *$ & $-0.003 * *$ & 0.001 & 0.001 \\
\hline & $(2.68)$ & $(2.55)$ & $(1.17)$ & $(1.50)$ \\
\hline Malaria & $-0.047 * * *$ & $-0.048 * * *$ & $-0.041 * * *$ & $-0.042 * * *$ \\
\hline & $(7.31)$ & $(7.52)$ & $(7.29)$ & $(7.50)$ \\
\hline Intensive & -0.017 & -0.018 & $-0.048 * * *$ & $-0.048 * * *$ \\
\hline & $(1.31)$ & $(1.39)$ & $(5.41)$ & $(5.42)$ \\
\hline Rural area $\left[\alpha_{4}\right]$ & $0.056 * * *$ & $0.052 * * *$ & $0.060 * * *$ & $0.052 * * *$ \\
\hline & $(5.09)$ & $(4.72)$ & $(5.95)$ & $(5.19)$ \\
\hline Rural*year $\left[\beta_{4}\right]$ & -0.021 & -0.019 & $-0.035 * * *$ & $-0.027 * *$ \\
\hline & $(1.41)$ & $(1.27)$ & $(2.71)$ & $(2.08)$ \\
\hline East & $0.042 * * *$ & $0.095 * * *$ & $0.054 * * *$ & $0.128 * * *$ \\
\hline & $(5.13)$ & $(8.44)$ & $(7.37)$ & $(11.51)$ \\
\hline North & $-0.043 * * *$ & $-0.038 * * *$ & -0.010 & $0.041 * * *$ \\
\hline & $(4.61)$ & $(3.05)$ & $(1.22)$ & $(3.11)$ \\
\hline West & $-0.062 * * *$ & $-0.043 * * *$ & $-0.024 * * *$ & $0.026 * *$ \\
\hline & $(7.16)$ & $(3.72)$ & $(3.10)$ & $(2.19)$ \\
\hline East*year & & $-0.094 * * *$ & & $-0.098 * * *$ \\
\hline & & $(7.27)$ & & $(9.40)$ \\
\hline North*year & & -0.007 & & $-0.068 * * *$ \\
\hline & & $(0.35)$ & & $(5.10)$ \\
\hline West*year & & $-0.038 * *$ & & $-0.073 * * *$ \\
\hline & & $(2.22)$ & & $(5.70)$ \\
\hline Observations & 13,966 & 13,966 & 15,430 & 15,430 \\
\hline Pseudo R-squared & 0.10 & 0.10 & 0.08 & 0.08 \\
\hline Log likelihood ratio & $-5,637$ & $-5,603$ & $-5,466$ & $-5,419$ \\
\hline$\chi^{2}$ for $\alpha_{1}+\beta_{1}=0$ & 8.28 & 7.31 & 0.01 & 0.04 \\
\hline Prob value & 0.004 & 0.007 & 0.754 & 0.842 \\
\hline$\chi^{2}$ for $\alpha_{2}+\beta_{2}=0$ & & & & 2.16 \\
\hline Prob value & & & & 0.141 \\
\hline$\chi^{2}$ for $\alpha_{3}+\beta_{3}=0$ & & & & 0.000 \\
\hline Prob value & & & & 0.987 \\
\hline$\chi^{2}$ for $\alpha_{4}+\beta_{4}=0$ & 12.64 & 11.50 & 9.77 & 10.10 \\
\hline Prob value & 0.000 & 0.001 & 0.002 & 0.002 \\
\hline
\end{tabular}

Absolute value of $\mathrm{z}$-statistics in parentheses

* significant at $10 \% ; * *$ significant at $5 \% ; * * *$ significant at $1 \%$ 
Table 7: Determinants of the incidence of sickness

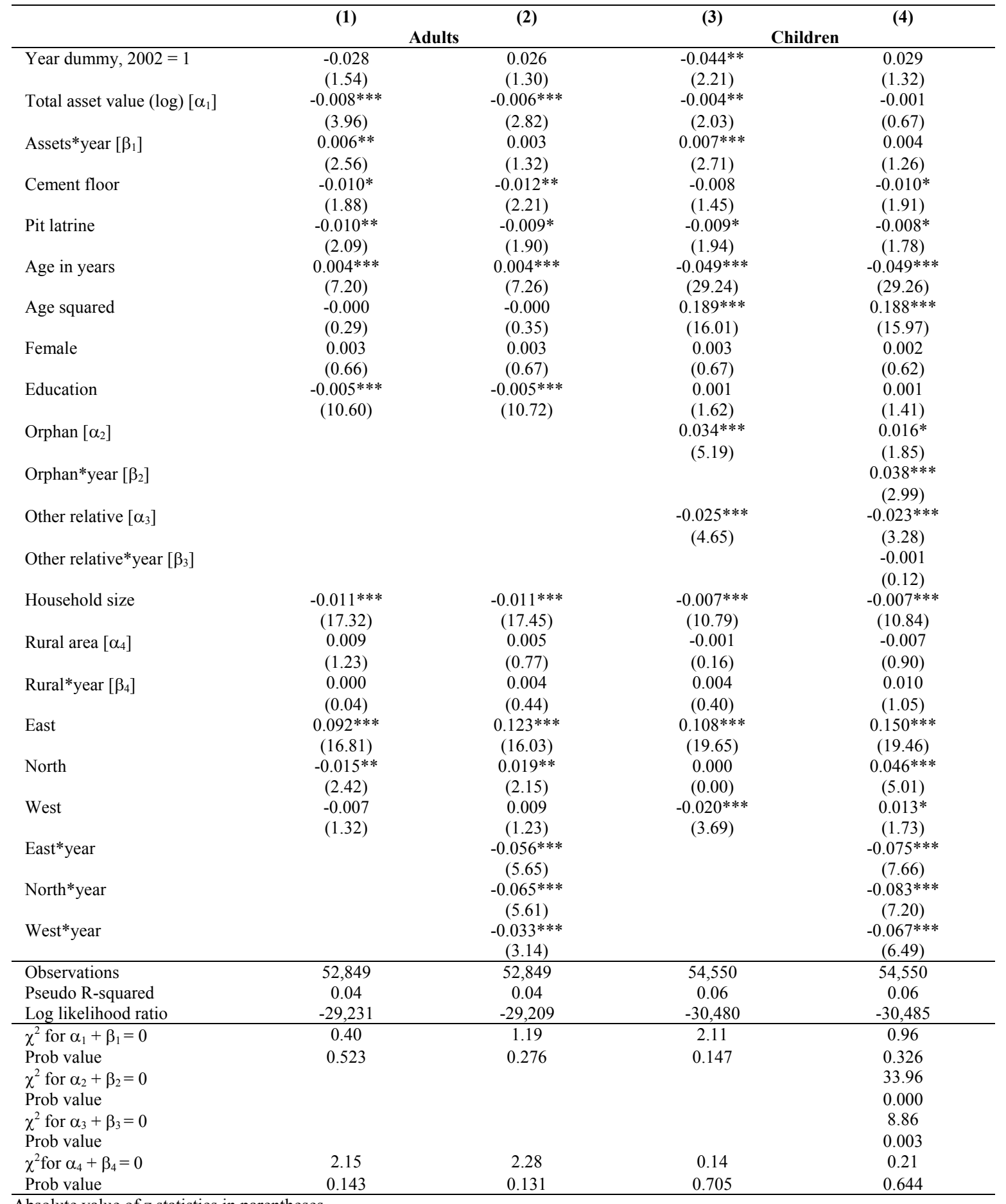

Absolute value of $\mathrm{z}$ statistics in parentheses

*significant at $10 \% ; * *$ significant at $5 \% ; * * *$ significant at $1 \%$ 
Table 8: Estimated benefits from the policy change

\begin{tabular}{ccccccc}
\hline \multicolumn{2}{c}{ Quintile Change in probability of falling sick } & \multicolumn{2}{c}{ Individual benefit (USh) } & \multicolumn{2}{c}{ Overall benefit (Mn US \$) } \\
& Adults & Children & Adults & Children & Adults & Children \\
\hline 1 & $2.76 \%$ & $4.54 \%$ & 2475.91 & 1073.39 & 3.691 & 2.008 \\
2 & $1.84 \%$ & $3.39 \%$ & 1792.52 & 874.48 & 2.447 & 1.470 \\
3 & $1.39 \%$ & $2.78 \%$ & 1346.42 & 728.36 & 1.473 & 0.890 \\
4 & $1.00 \%$ & $2.20 \%$ & 921.95 & 561.97 & 0.944 & 0.632 \\
5 & $0.56 \%$ & $1.61 \%$ & 430.90 & 406.49 & 0.382 & 0.047 \\
Total & $1.46 \%$ & $2.99 \%$ & 1337.79 & 750.23 & 8.937 & 5.047 \\
\hline
\end{tabular}

Source: Own computation based on the regression results reported earlier. 


\section{References}

Ablo, E. and R. Reinikka, 1998. "Do budgets really matter? Evidence from public spending on education and health in Uganda," World Bank Research Paper No. 1926. The World Bank, Washington D.C.

Akin, John and P. Hutchinson, 1999. "Health care facility choice and the phenomenon of bypassing," Health Policy and Planning. 14:2, pp. 135-151.

Akin, J.S., C.C. Griffith, D.K. Guilkey and B.M. Popkin, 1985. The demand for primary health services in the Third World. Rowan and Allenheld, Totawa, NJ.

Akin, John S., H Guilkey, P. Hutchinson, and J. McIntosh, 1989. "Price elasticities of demand for curative health care with control for sample selectivity on endogenous illness: An analysis for Sri Lanka," Health Economics. 7:6, pp. 509-31.

Appleton, S. 2001. “The Rich Are Just Like Us, Only Richer’: Poverty Functions or Consumption Functions?” Journal of African Economies. 10:433-469.

Asenso-Okyere. W., A. Anum, I. Osei-Akoto and A. Adukonu, 1998. "Cost recovery in Ghana: Are there any changes in health care seeking behaviour?” Health Policy and Planning. 13, pp. 181-188.

Audibert, M., and J. Mathonnat, 2000. “Cost recovery in Mauritania, initial lessons,” Health Policy and Planning. 15, pp. 66-75.

Birdsall, N. and F,. Orivel, 1983. "The demand for and willingness to pay for health and schooling in Mali." The World Bank, Washington D.C.

Chawla, M. and R.P. Ellis, 2000. "The impact of financing and quality changes on health care demand in Niger," Health Policy and Planning. 2000 15, pp. 76-84.

Creese, A.L. 1991. "User charges for health care: A review of recent experiences.” Health Policy and Planning, 6:4, pp. 309-19.

de Ferranti, D., 1985. "Paying for health services in developing countries: A review," Staff working paper No. 721. The World Bank, Washington D.C.

Gwatkin, D.R., 2000. Health inequalities and the health of the poor : What do we know? What can we do? Bulleting of the World Health Organisation. 78(1) pp.3-18.

Gertler, P. and J. van der Gaag, 1990. The Willingness to Pay for Medical care: Evidence from two Developing Countries. Baltimore: The John Hopkins University Press.

Gilson, L., D. Kalyalya, F. Kuchler, S. Lake, H. Oranga and M. Ouendo, 2000. "The equity impacts of community financing activities in three African countries," International Journal of Health Planning and Management. Vol. 15, pp. 291-317.

Hausmann-Muela, S., A.K. Mushi and J.M. Ribera, 2000. "The paradox of the cost and affordability of traditional and government health services in Tanzania," Health Policy and Planning. 15, pp. 296-302.

Heller, P.S., 1982. "A model of the demand for health services in Peninsular Malaysia." Social Science and Medicine, 16, pp. 267-84.

Jimenez, F., 1985. Pricing policy in the social sectors. Baltimore: The John Hopkins University Press.

Kapiriri, L., O.F. Norheim and K. Heggenhougen, 2003. "Public participation in health planning and priority setting at the district level in Uganda.” Health Policy and Planning. 18(2), pp.205-213.

Killingsworth J., N. Hossain, Y. Hedrick-Wong, S. Thomas, A. Rahman, and T. Begum, 1999. "Unofficial fees in Bangladesh: Price, equity and institutional issues," Health Policy and Planning. 14, pp. 152-163.

Kivumbi, G.W. and F. Kintu, 2002. "Exemptions and waivers from cost sharing: Ineffective safety nets in decentralised districts in Uganda." Health Policy and Planning. 17 (Supplementary 1), pp. 64-71.

Lendlow, M., R. Reinikka and J. Svensson, 2003. "Health Care on the Frontlines." Africa region Human Development Working Paper Series, The World Bank, Washington D.C.

Litvak, J. and C. Bodart, 1993. "User fees plus quality equals improved access to health care: Results of a field experiment in Cameroon," Social Science and Medicine. 37: pp. 369-83.

McPake, B., 1993. "User charges for health services in developing countries: A review of the economic literature." Social Science and Medicine, 36:11, pp. 1397-1405.

, K. Hanson and A. Mills, 1993. "Community financing of health care in Africa: An evaluation of the Bamako Initiative." Social Science and Medicine, 36:11, pp. 1393-95. 
MOH, 1997. The financial management guidelines for cost sharing in public hospitals. Ministry of Health. Kampala, Uganda.

Mwesigye, F., 2002. "Removal of cost-sharing /cost recovery in health - helping or hurting the poor?" A report conducted for the Uganda national NGO-Forum.

Nyonator, F. and J. Kutzin, 1999. "Health for some? The effects of user fees in the Volta Region of Ghana," Health Policy and Planning. 14, pp. 329-341.

Reddy, S. and J. Vandermoortele, 1996. "User financing of basic social services: A review of theoretical arguments and empirical evidence," UNICEF Staff Working Papers, Evaluation, Policy, and Planning Series, New York.

Reinikka, R. and J. Svensson, 2003. "Working for God? Evaluating service delivery of religious not-for-profit health care providers in Uganda.” Policy Research Working Paper No. 3058, The World Bank, Washington D.C.

Republic of Uganda, 2001. Annual Health Sector Performance Report Financial Year 2000/2001. Ministry of Health, Kampala. 2000a. Health Sector Strategic Plan, 2000/01 - 2004/05. Ministry of Health, Kampala , 2000b. Statistical Abstract, 2000. Ministry of Health, Kampala. 1997. Inventory of Health Services in Uganda for the Year 1997. Ministry of Health, Kampala.

Shaw, R.P. and M. Ainsworth, 1995. "Financing Health Services through User Fees and Insurance, Case Studies from SubSaharan Africa,” World Bank Discussion Papers 294, Washington D.C.

UBOS, 2001. Uganda National Household Survey 1999/00 Report. Entebbe: Uganda Bureau of Statistics. 